\title{
Development of simple and sensitive HPLC method for determination of glyphosate residues in soybean
}

\author{
Om Prakash Sharma ${ }^{1 *}$, Nanthanit Pholphana ${ }^{2}$, Nuchanart Rangkadilok ${ }^{1,2,}$, \\ Preeda Parkpian ${ }^{3}$ and Jutamaad Satayavivad ${ }^{1,2}$
}

\author{
${ }^{1}$ Environmental Toxicology Programme, Chulabhorn Graduate Institute, Vibhavadee-Rangsit Highway, \\ Laksi, Bangkok 10210 THAILAND \\ ${ }^{2}$ Laboratory of Pharmacology, Chulabhorn Research Institute, Vibhavadee-Rangsit Highway, \\ Laksi, Bangkok 10210 THAILAND \\ ${ }^{3}$ School of Environment, Resources and Development, Asian Institute of Technology, P.O. Box 4, \\ Klong Luang, Pathumthani 12120 THALAND
}

\begin{abstract}
The purpose of this study was to develop a simple and sensitive high performance liquid chromatography (HPLC) method for determination of glyphosate (GP) residues in soybean grains. From soybean matrix, glyphosate was extracted with a mixture of water and methanol $(4: 1, \mathrm{v} / \mathrm{v})$ from soybean samples followed by protein precipitation with equal volume of methanol. No preconcentration and further clean up of the sample were required. Pre-column derivatization was carried out with excess amount of 9fluorenylmethyl chloroformate (FMOC-Cl) in the presence of borate buffer. The gradient program developed in this method was successfully applied to a reverse phase HPLC system with a $\mathrm{C}_{8}$ column (ACE $5 \mu \mathrm{m} 4.6 \times 250 \mathrm{~mm}$ ), and eluted with a mobile phase consisting of $50 \mathrm{mM}$ phosphate buffer, $\mathrm{pH} 2.5$, and acetonitrile at the flow rate of $0.8 \mathrm{ml} / \mathrm{min}$ and fluorescence detection. Parameters and conditions affecting extraction, derivatization reaction and chromatographic separation were systematically examined. Linearity of the method ranged from $0.005-1.0 \mu \mathrm{g} / \mathrm{ml}$. The correlation coefficient $\left(r^{2}\right)$ of calibration curve for glyphosate in soybean sample was found to be 0.99929 . The limit of detection (LOD) and limit of quantitation (LOQ) values were determined to be $0.125 \mathrm{mg} / \mathrm{kg}$ and $0.25 \mathrm{mg} / \mathrm{kg}$, respectively. Average recovery was $95.2 \%$. Repeatability and intermediate precision calculated on the basis of peak area were excellent and showed relative standard deviation ranged from 0.15 $1.29 \%$ and $1.15-3.87 \%$, respectively. The developed method has been successfully applied for determination of glyphosate residues in soybean grains obtained from Thailand and Nepal. Soybean samples (53) from two different lots were analyzed and glyphosate residues ranged from $0.23 \mathrm{mg} / \mathrm{kg}$ to $5.06 \mathrm{mg} / \mathrm{kg}$. Almost $50 \%$ soybean samples contained nearly consistent residue levels in both lots but in remaining samples there was a significant variation of glyphosate levels between two lots. Relatively higher residues were detected in samples from Thailand (0.27-5.06 mg/kg) compared to Nepal $(0.23-0.99 \mathrm{mg} / \mathrm{kg})$. The results suggest that the proposed method can be used to determine glyphosate residues in foods derived from soybean and other crops such as corn, cotton, wheat, etc. where glyphosate is widely applied to these crops.
\end{abstract}

Key words: HPLC, Glyphosate, Soybean, Fluorescence detection, FMOC-Cl

\section{Introduction}

Glyphosate (GP) is a post-emergent, nonselective, systemic and foliar applied herbicide that inhibits amino acid metabolism in plants by disr upting the shikimic acid biochemical pathway . Glyphosate has been one of the world's most widely used herbicide in agricultural as well as in non-agricultural sectors. Due to its widespread use across the world, environmental exposure to glyphosate has become extensive and there is increasing concern of its contamination in water, soil and food.
It is considered that glyphosate is less toxic to animals. Therefore, its application is scaled up very rapidly in varieties of crops such as soybeans, corn, cotton, etc., fruits and vegetables. Presence of glyphosate in food is further increased with the introduction of edible transgenic crops and fr uits that have been designed to tolerate high levels of this compound. Some studies have raised serious concern over the safety of its contamination in food. Evidence of its toxicity has been emerging for the past decades. 
The herbicide has already been linked with spontaneous abortions (Arbuckle et al., 2001), non-Hodkin's lymphoma (Hardell and Eriksson, 1999) and multiple myeloma (Roos et al., 2005) in humans. Recent studies have shown that glyphosate is associated with endocrine disruption, developmental toxicity and reproductive disorder (Gasnier et al., 2009; Oliveria et al., 2007; Benachour et al., 2009; Benachour \& Seralini, 2009; Richard et al., 2005).

Soybeans are the world's foremost provider of variety of soy protein products such as soy flour and soy milk. Soybean meal is also a leading protein and energy source for animal feeds. People eat soybean and soybean derived food as their protein source and thus may be at risk of glyphosate exposure. Therefore, presence of glyphosate residues in soybeans and soybean derived food is a serious public health concern.

Detection of glyphosate residues in the environment and food is laborious and expensive. Owing to its physicochemical properties such as high water solubility and ionic character, it is very difficult to establish simple methodologies to extract and deter mine glyphosate in different environmental media including food matrixes (Peruzzo et al., 2008). Absence of chromophore and fluorophore groups (Schrübbers et al., 2015) in the glyphosate molecule is another problem in chromatographic analysis. Again, structural similarity of glyphosate to naturally occur ring amino acids and small amino sugars contributes to the difficulties of residue analysis in food samples. Numbers of research papers on analytical methodologies for glyphosate residue determination in water and soil samples have been published but quite limited literatures are available describing analysis of glyphosate in food samples. However, a great variety of analytical methods have been developed to determine the residues of glyphosate and its major metabolite, aminomethylphosphonic acid (AMPA), in various sample matrixes. Reported analytical techniques used for glyphosate analysis mainly consists of thin layer chromatograpy , liquid chromatography, ion exchange chromatography, enzyme linked immuno-sorbent assays (ELISA) capillar y electrophoresis and nuclear magnetic resonance (NMR) spectroscopy methods. Although, glyphosate lacks chromophore or fluorophore groups, HPLC analytical technique is considered to be the most favorable method for the detection and quantification of glyphosate in various environmental media over other analytical methods (Ibanez et al., 2005). Similarly, its low volatility and high ionic character favor for HPLC analysis.

\section{Materials and methods}

Two different lots of soybean samples were collected from local markets in Thailand and Nepal. Organic soybean was used as a blank sample for the experiment. Glyphosate was extracted with water-methanol (4:1, v/v) from soybean samples followed by protein precipitation with equal volume of methanol and 5-fold dilution with water. Before HPLC analysis, glyphosate was derivatized with FMOC-Cl $(2 \mathrm{~g} / \mathrm{L}$ in acetonitrile $)$ at $40{ }^{\circ} \mathrm{C}$ in the presence of $50 \mathrm{mM}$ borate buffer ( $\mathrm{pH}$ 9.5). Reaction was stopped by $2 \% \mathrm{H}_{3} \mathrm{PO}_{4}$ after overnight reaction. Separation was carried out on $\mathrm{C}_{18}$ reverse phase HPLC column (ACE $5 \mu \mathrm{m} 4.6$ x $250 \mathrm{~mm}$ ), and eluted with a mobile phase consisting of $50 \mathrm{mM}$ phosphate buffer ( $\mathrm{pH} 2.5)$ and acetonitrile (CAN) at the flow rate of 0.8 $\mathrm{ml} / \mathrm{min}$ and fluorescence detection set at emission wavelength of $325 \mathrm{~nm}$ with excitation at $270 \mathrm{~nm}$.

Calibration experiments were carried out in both solvent standard (deionized water) and matrix-matched standards to compare matrix effect. Linearity of the method was deter mined by using calibration solutions ranging from $0.005-1.0 \mu \mathrm{g} / \mathrm{ml}$. The limits of detection (LOD) and quantitation (LOQ) were also determined. The method was validated analysing or ganic soybean sample spiked at three concentrations $(0.05,0.1$ and $0.5 \mu \mathrm{g} / \mathrm{ml})$. T o determine the \% recovery, six replicates of pre-spiked samples for each concentration were analyzed. To evaluate the repeatability, post-spiked six replicates for each concentration were injected in the same day and for intermediate precision injection were made on three different days. Matrix-matched external standard method was used for the quantitative analysis of glyphosate.

\section{Results and discussion \\ Selection of extracting solvents}

In this study, methanol-water was established as an effective solvent system to extract glyphosate from soybean matrix. It can remove the protein content of the soybean and provide satisfactor $y$ sensitivity and recovery.

\section{Derivatization}

The developed method is based on the derivatization of glyphosate with FMOC-Cl followed by HPLC analysis with fluorescent detection. In this study, derivatization reaction with three different concentrations (1, 2 and $5 \mathrm{~g} / \mathrm{L}$ in acetonitrile) of FMOC -Cl for different time course (15 min, $30 \mathrm{~min}, 1 \mathrm{hr}, 2 \mathrm{hr}$ and overnight), and in the presence of borate buffer with $\mathrm{pH} 8.5,9$ and 9.5 were studied. It has been found that derivatization reaction with $2 \mathrm{~g} / \mathrm{L}$ FMOC-Cl at $40^{\circ} \mathrm{C}$ for overnight time course in the presence of borate buffer with $\mathrm{pH} 9.5$ showed better performance in the sense of peak shape and sensitivity (Fig. 2, 3).
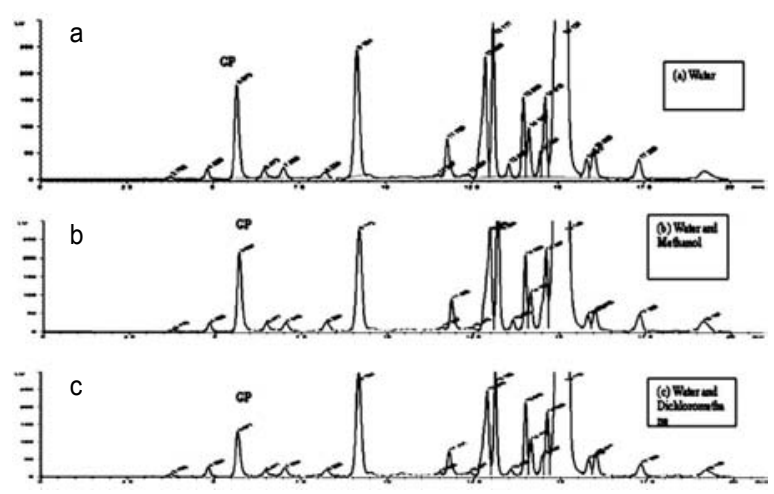

Fig. 1 Chromatograms of soybean extract extracted from (a) water (b) water + methanol and (c) water + dichloromethane 


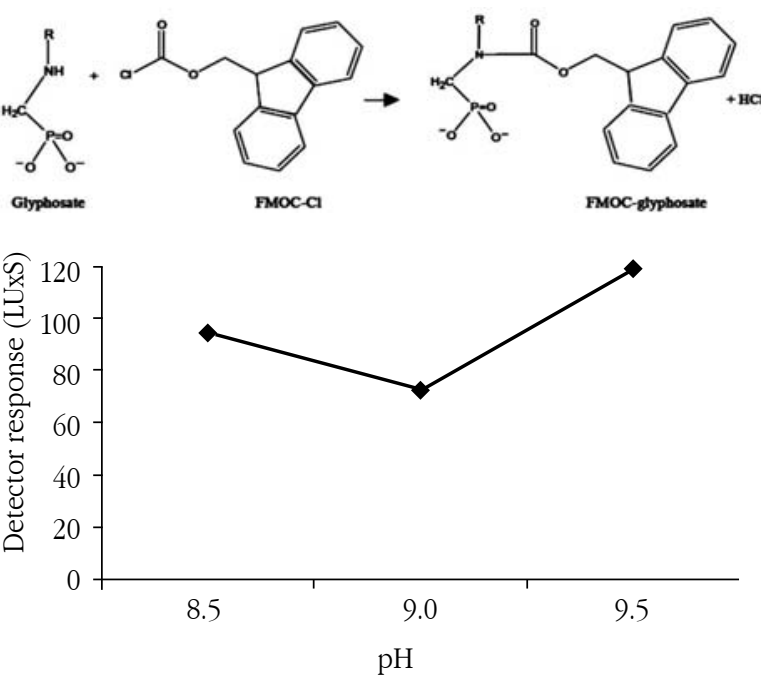

Fig. 2 Effect of $\mathrm{pH}$ of the borate buffer on derivatization reaction

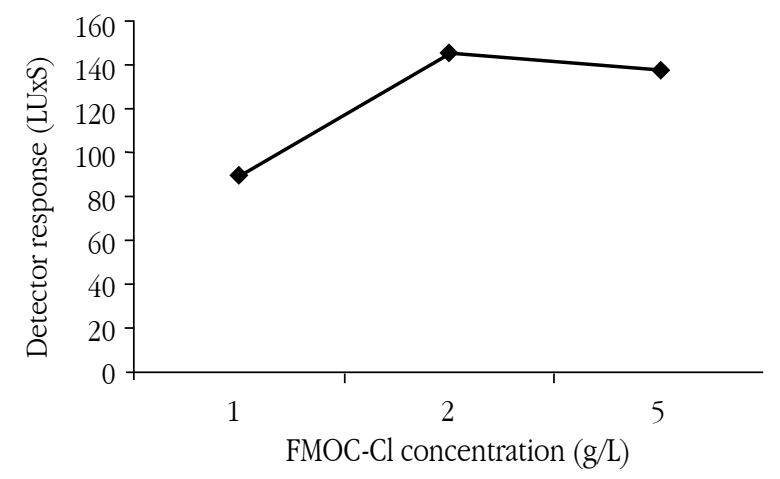

Fig. 3 Effect of FMOC-Cl concentration on derivatization

\section{Chromatographic separation and HPLC conditions}

Phosate buffer (A) and acetonitrile (B) were used as mobile phase. Phosphate buffer $(50 \mathrm{mM}$ ) with pH 2.5 and $\mathrm{pH} 5.75$ were compared to achieve good separation. From the result, it was found that the phosphate buffer with $\mathrm{pH} 5.75$ gave less retention time and may co-eluted or inter fered with other unretained compounds. A mixture of $50 \mathrm{mM}$ phosphate buffer, $\mathrm{pH} 2.5$ and acetonitrile (65:35, $\mathrm{v} / \mathrm{v}$ ) was optimized to provide more efficient separation of derivatized glyphosate from complex soybean matrix (Fig. 4).

\section{Calibration and linearity}

Linearity of the calibration was evaluated from both solvent standard and matrix-matched standard (Fig. 5). Matrix-matched standards contained more interferrents from sample than solvent standards which can react with derivatizing reagent and produce interference during analysis.

The calibration was per formed using exter nal matrix matched calibration solutions ranging from $0.005-1.0 \mu \mathrm{g} / \mathrm{ml}$ (Fig. 6).

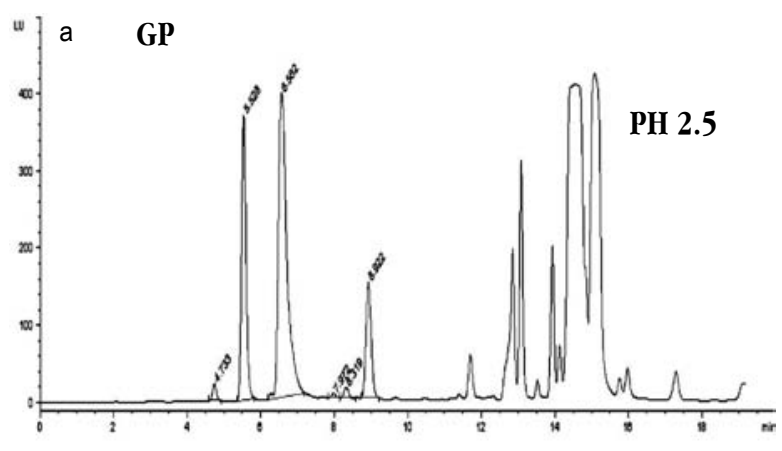

GP

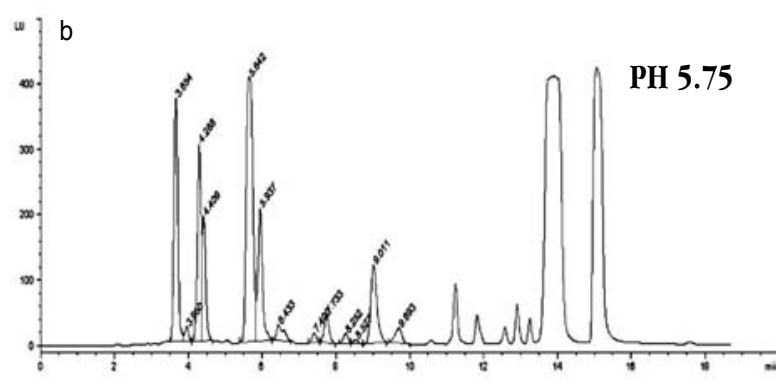

Fig. 4 Chromatograms after spiking standard glyphosate in blank soybean extract using $50 \mathrm{mM}$ phosphate bufferwith (a) pH 2.5 and (b) pH 5.75
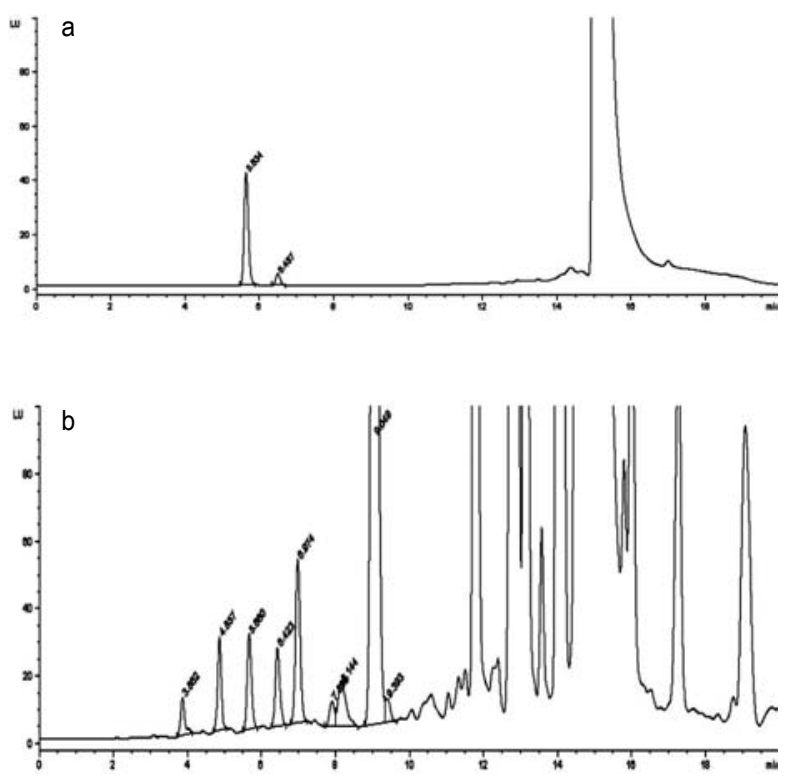

Fig. 5 Chromatograms of standard glyphosate in (a) Solvent standard and (b) Matrix-matched standard. 

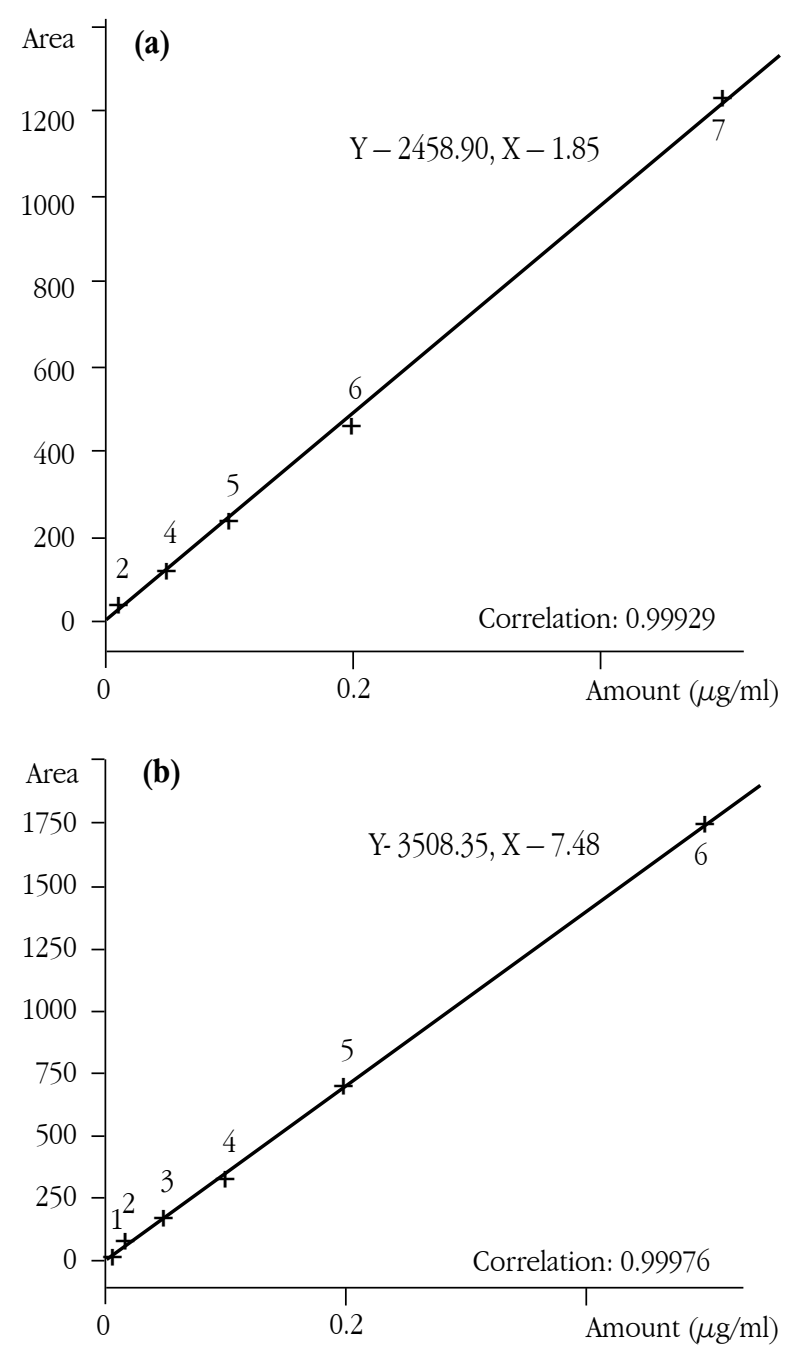

Fig. 6 Calibration curve of standard glyphosate in (a) Deionized water and (b) Matrix-matched solution.

\section{Recoveries and precision}

Table 1 Results from inter-day and intra-day precision

\begin{tabular}{|c|c|c|c|c|}
\hline \multirow{2}{*}{$\begin{array}{l}\text { Concentration } \\
(\mu \mathrm{g} / \mathrm{ml})\end{array}$} & \multicolumn{2}{|c|}{ Intra-day (\% RSD) } & \multicolumn{2}{|c|}{ Inter-day (\% RSD) } \\
\hline & PA (LUxS) & $\mathrm{RT}$ (min) & PA (LUXS) & $\mathrm{RT}(\mathrm{min})$ \\
\hline 0.05 & 1.29 & 0.44 & 1.87 & 1.24 \\
\hline 0.1 & 0.84 & 0.18 & 3.87 & 1.34 \\
\hline 0.5 & 0.15 & 0.30 & 1.15 & 1.23 \\
\hline
\end{tabular}

Table 2 Recovery results

\begin{tabular}{ccc}
\hline Analyte Spiked Level $(\boldsymbol{\mu} \mathbf{g} / \mathbf{m l})$ & \% Recovery & Average Recovery \\
\hline 0.05 & 100.9 & \\
0.1 & 92.47 & $95.2 \%$ \\
0.5 & 92.23 & \\
\hline
\end{tabular}

Concentration of derivatizing agent, $\mathrm{pH}$ of the reaction medium, time course and temperature of the reaction are critical conditions that may determine extent of reaction between glyphosate and derivatizing reagent $(\mathrm{FMOC}-\mathrm{Cl})$ as well as production of interferrents such as FMOC-OH and other fluorogenic compounds. Derivatization reaction with optimized conditions in the present study has shown better per formance in the sense of sensitivity and peak shape with reduced interference over other conditions of derivatization reported in previous studies (Nedelkoska \& Low, 2004; Hogendoorn et al., 1999; Bo et al., 2007; Ibanez et al., 2005).

The developed method has shown higher sensitivity over other methods that use same derivatizing agent and detector for the same nature of analyte. Hogendoorn et al. (1999) have established LOD at $0.5 \mathrm{mg} / \mathrm{kg}$ in cereal grains using coupled-column liquid chromatography with fluorescent detection af ter pre-column FMOC-Cl derivatization while LOD and LOQ in soybean in the present study were 0.125 and $0.25 \mathrm{mg} / \mathrm{kg}$, respectively. Similarly, the present detection limit was also lower than LOD $(0.3 \mathrm{mg} / \mathrm{kg})$ established by Nedelk oska and Low (2004) where glyphosate residues in grass were analysed by using high performance liquid chromatography with fluorescent detection (HPLC-FLD). Sensitivity obtained in the proposed method for complex matrix is comparable to the sensitivity established by liquid chromatography coupled to mass detector. LOQ of our method was lower to the LOQ ( 0.3 $\mathrm{mg} / \mathrm{kg}$ ) established by Junior et al. (2009) where glyphosate was analyzed in soybean grain using liquid chromatography/mass spectrometry/mass spectrometry (LC-MS/MS) method.

Residues determined in soybean samples from Thailand and Nepal ranged from $0.27-5.06 \mathrm{mg} / \mathrm{kg}$ and $0.23-0.99 \mathrm{mg} / \mathrm{kg}$, respectively (Table 3). Comparing the two different lots, $50 \%$ soybean samples contained nearly consistent levels but in remaining samples, residues were different between the two lots. Variation of glyphosate residues between two different lots may be due to different application pattern, harvesting time after treatment and storage temperature and conditions. Higher residues in samples from Thailand may be due to widespread application of glyphosate in soybean fields compared to Nepal where use of glyphosate is more limited.

\section{Residues}

Developed HPLC method was applied for the deter mination of glyphosate residues in soybean samples. Residues determined in soybean samples from Thailand and Nepal ranged from 0.27 - 5.06 $\mathrm{mg} / \mathrm{kg}$ and $0.23-0.99 \mathrm{mg} / \mathrm{kg}$, respectively (Table 3).

\section{盽 TU-CDES}


Table 3 Glyphosate residues in soybean sample

\begin{tabular}{ccc}
\hline Soybean sample ID & \multicolumn{2}{c}{ Glyphosate residue $(\mathbf{m g} / \mathbf{k g}) \pm$ SD $(\mathbf{n}=\mathbf{3})$} \\
\cline { 2 - 3 } & Lot.No. 1 & Lot. No. 2 \\
\hline SB-01 & $0.47 \pm 0.09$ & $0.27 \pm 0.03$ \\
SB-02* & $0.23 \pm 0.00$ & - \\
SB-03 & $1.16 \pm 0.08$ & $1.63 \pm 0.08$ \\
SB-04 & $0.31 \pm 0.02$ & - \\
SB-05 & $1.21 \pm 0.02$ & $1.22 \pm 0.15$ \\
SB-06 & $0.66 \pm 0.18$ & $0.99 \pm 0.05$ \\
SB-07 & $0.89 \pm 0.00$ & $0.93 \pm 0.01$ \\
SB-08 & $0.97 \pm 0.03$ & $0.86 \pm 0.01$ \\
SB-09 & $0.45 \pm 0.02$ & $0.31 \pm 0.09$ \\
SB-10 & $2.88 \pm 0.02$ & $2.99 \pm 0.40$ \\
SB-11 & $0.67 \pm 0.08$ & $0.68 \pm 0.08$ \\
SB-12 & $0.24 \pm 0.02$ & $0.39 \pm 0.01$ \\
SB-13 & $4.25 \pm 0.16$ & $5.06 \pm 0.08$ \\
SB-14 & $1.47 \pm 0.09$ & $1.65 \pm 0.00$ \\
SB-15 & $2.02 \pm 0.05$ & $2.28 \pm 0.23$ \\
SB-16 & $1.09 \pm 0.05$ & $0.73 \pm 0.02$ \\
SB-17 & $0.73 \pm 0.04$ & $0.50 \pm 0.04$ \\
SB-18 & $0.58 \pm 0.00$ & $1.09 \pm 0.04$ \\
SB-19 & $2.22 \pm 0.11$ & $1.05 \pm 0.06$ \\
SB-20 & $0.52 \pm 0.04$ & $0.78 \pm 0.02$ \\
SB-21 & $0.35 \pm 0.01$ & $0.93 \pm 0.02$ \\
SB-22 & $1.79 \pm 0.10$ & $2.05 \pm 0.06$ \\
SB-23 & $1.89 \pm 0.08$ & $1.70 \pm 0.13$ \\
SB-24 & $1.24 \pm 0.13$ & $1.00 \pm 0.02$ \\
SB-25 & $0.25 \pm 0.01$ & - \\
SB-26* & $0.38 \pm 0.01$ & - \\
SB-27* & $0.57 \pm 0.03$ & $0.99 \pm 0.03$ \\
SB-28* & $0.53 \pm 0.01$ & - \\
SB-29* & $0.46 \pm 0.01$ & $0.63 \pm 0.06$ \\
Range & $\mathbf{0 . 2 3 - 4 . 2 5}$ & $\mathbf{0 . 2 7} \boldsymbol{- 5 . 0 6}$ \\
\hline & &
\end{tabular}

$*$ = Sample from Nepal - = No sample

\section{Conclusion}

The present results suggest that the proposed method can be used to analyse glyphosate residues not only in soybean grains but also in soybean derived food and other crop matrixes such as corn, wheat, cotton etc. where glyphosate is widely applied. Because of the high sensitivity of this method, it can be also used to analyze glyphosate residues in water . Higher residues of glyphosate in samples from Thailand compared to Nepal suggested that the presence of glyphosate residues in soybean and soybean derived food is increasing with its increased use. Therefore, there is an urgent need to monitor glyphosate residues in soybean derived food as well as in food derived from other crops and water.

\section{Acknowledgements}

The authors are thankful to laboratory of pharmacology, Chulabhorn research institute, Thailand for providing laborator y facility to carry out the work. One of the authors (OP Shar ma) would like to express sincere gratitude to the Thailand Inter national Cooperation Agency (TICA), Royal Thai Government for providing financial support in the form of scholarship and National Forensic
Science L aboratory, Ministr y of Environment, Science and Technology, Nepal for providing opportunity to carry out this work.

\section{References}

Arbuckle T E, Lin Z, Mery LS (2001). An exploratory analysis of the effect of pesticide exposure on the risk of spontaneous abortion in an Ontario farm population. Environmental Health Perspectives, 109, 851-857.

Benachour N, Seralini GE (2009). Glyphosate formulations induce apoptosis and necrosis in human umbilical, embryonic, and placental cells. Chemical Research in Toxicology, 22, 97-105.

Benachour N, Sipahutar H, Moslemi S, Gasnier C, Travert C, Seralini GE (2007). Time and dose-dependent effects of Roundup on human embryonic and placental cells. Environmental Contamination and Toxicology, 53, 126-133.

Bo L, Xiaojun D, Dehua G, Shuping J (2007). Determination of glyphosate and aminomethyl phosphonic acid residues in food using high performance liquid chromatography-mass spectrometry/mass spectrometry. Chinese Journal of Chromatography, 25(4), 486-490.

Chen M.X., Cao Z.Y., Jiang Y., Zhu Z.W. (2013). Direct determination of glyphosate and its major metabolite, aminomethylphosphonic acid, in fruits and vegetables by mixed-mode hydrophilic interaction/weak anion-exchange liquid chromatography coupled with electrospray tandem mass spectrometry. Journal of Chromatography A, 1272, 90-99.

Coutinho CFB, Coutinho LFM, Mazo LH, Nixdorf SL, Camara CAP (2008). Rapid and direct determination of glyphosate and aminomethylphosphonic acid in water using anion-exchange chromatography with coulometric detection. Journal of Chromatography A, 120, 246-249.

Fu W, Guo Q, Wang J (2010). Solubility of glyphosate in ethano l+ water, 1-propanol + water and 2-propanol + water from (293233K). J. Chem. Eng. Data 55, 3915-3917.

Gasnier C, Dumont C, Benachour N, Clair E, Chagnon M, Seralini GE (2009). Glyphosate based herbicides are toxic and endocrine disruptors in human cell lines. Toxicology, 262, 184-191.

Hardell L, Eriksson M (1999). A case-control study of non-Hodgkin lymphoma and exposure to pesticides. Cancer, 85(6),13531360 .

Hogendoorn EA, Ossendrijver FM, Dijkman E, Baumann RA (1999). Rapid determination of glyphosate in cereal samples by means of pre-column derivatization with 9-fluorenylmethyl chloroformate and coupled-column liquid chromatography with fluorescence detection. Journal of Chromatography A, 833, 67-73.

Ibanez M, Pozo OJ, Sancho JV, Lopez FJ, Hernandez F (2006). Reevaluation of glyphosate determination in water by liquid chromatography coupled to electrospray tandem mass spectrometry. Journal of Chromatography A, 1134, 51-55. 
Ibanez M, Pozo OJ, Sancho JV, Lopez FJ, Hernandez F. (2005) Residue deter mination of glyphosate, glufosinate and aminomethylphosphonic acid in water and soil samples by liquid chromatography coupled to electrospray tandem mass spectrometry. Journal of Chromatography A, 1081, 145-155. Junior HAM, Lebre DT, Wang AY, Pires MAF, Bustllos OV (2009). An alternative and fast method for determination of glyphosate and aminomethyphosphonic acid (AMPA) residues in soybean using liquid chromatography coupled with tandem mass spectrometry. RCM Spectrum, 23, 1029-1034.

Kaczynski P, Lozowicka B (2015). Liquid chromatographic determination of glyphosate and aminomethylphosphonic acid residues in rapeseed with MS/MS detection or derivatization/fluorescence detection. Open Chem, 13, 10111019.

Küsters M., Gerhartz M (2010). Enrichment and low-level determination of glyphosate, aminomethylphosphonic acid and glufosinate in drinking water after cleanup by cation exchange resin. J. Sep. Sci., 33, 1139-1146.

Nedelkoska TV, Low GK-C (2004). High performance liquid chromatographic determination of glyphosate in water and plant material after pre-column derivatization with 9-fluorenylmethyl chloroformate. Analytica Cbimica Acta, 511, 145-153.

Oliveria AG, Telles LF, Hess RA, Mahecha GAB, Oliveria CA (2007). Effects of herbicide Roundup on the epididymal region of drakes Anas platyrbynchos. Reproductive Toxicology, 23, 182191.

Peruzzo PJ, Porta AA, Ronco AE (2008). Levels of glyphosate in surface waters, sediments and soils associated with direct sowing soybean cultivation in north Pampasic region of Argentina. Environmental Pollution, 156, 61-66.

Piriyapittaya M, Jayanta S, Mitra S, Leepipatpiboon N (2008). Microscale membrane extraction of glyphosate and aminomethylphosphonic acid in water followed by highperformance liquid chromatography and post column derivatization with fluorescence detector. Journal of Chromatography A, 1189, 483-492.
Qian K., Tang T., Shi T., Wang F., Li J., Cao Y. (2009). Residue determination of glyphosate in environmental water samples with high-performance liquid chromatography and UV detection after derivatization with 4-chloro-3,5dinitrobenzotrifluoride. Anal. Chim. Acta., 635, 222-226.

Rasul Jan M, Shah J, Muhammad M, Ara B (2009). Glyphosate herbicide residue determination in samples of environmental importance using spectrophotometric method. Journal of Hazardous Materials, 169, 742-745.

Richard S, Moslemi S, Sipahutar H, Benachour N, Seralini G-E (2005). Differential effects of glyphosate and Roundup on human placental cells and aromatase. Environmental Health Perspectives, 113, 716-720.

Roy D N, Konar S K (1989). Development of an analytical method for the determination of glyphosate and aminomethylphosphonic acid in crops. Journal of Agricultural and Food Chemistry, 37, 441.

Schrübbers LC, Masís-Mora M, Rojas E C, Galverde B E, Christensen J H, Cedergreen N (2016). Analysis of glyphosate and aminomethylphosphonic acid in leaves from Coffea arabica using highperformance liquid chromatography with quadrupole mass spectrometry detection.Talanta, 146, 609620.

Tsui MTK, Chu LM (2008). Environmental fate and non target impact of glyphosate based herbicide (Roundup) in a subtropical wetland. Chemosphere, 71, 439-446.

Wang K C, Chen S M, Hsu J F, Cheng S G, Lee C K (2008). Simultaneous detection and quantitation of highly watersoluble herbicides in serum using ion-pair liquid chromatography-tandem mass spectrometry. Journal of Chromatography B, 876, 211-218.

Zelenkova NF, Vinokurova N G (2008). Determination of glyphosate and its biodegradation products by chromatographic methods. Journal of Analytical Chemistry, 63, 871-874. 